\title{
Empréstimos de conjunções e subordinadores do Português em Nheengatu
}

DOI: http://dx.doi.org/10.21165/el.v50i1.2928

\author{
Gláucia Vieira Cândido' \\ Aline da $\mathrm{Cruz}^{2}$ \\ Giovana Alves de Oliveira ${ }^{3}$
}

\section{Resumo}

Estudos demonstram que os empréstimos linguísticos também ocorrem em classes gramaticais, como a das conjunções, conforme Muysken (1981) e Matras (2009), embora sejam mais comuns em classes lexicais. Por isso, este artigo discute a acessibilidade de conjunções a se manifestarem como empréstimos. Para tanto, faz-se uma análise dos empréstimos de conjunções do Português Brasileiro (PB) que são utilizadas em Nheengatu (NG). A partir da comparação entre dados, foram identificados empréstimos como o da adversativa "mas" (em Nheengatu, "ma") e do advérbio de tempo dêitico "agora", que adquiriu, em um processo de gramaticalização, também a função de conjunção de ressalva, a qual foi transportada para o NG. Pôde-se confirmar a abertura das línguas para empréstimos de conjunções e que termos de funções ambíguas no PB são transportados com função mais delimitada para o NG.

Palavras-chave: contato linguístico; empréstimo; conjunções; Português Brasileiro; Nheengatu.

\footnotetext{
1 Universidade Federal de Goiás (UFG), Goiânia, Goiás, Brasil; glaucia.v@uol.com.br; http://orcid.org/0000-0002-3790-9192

2 Universidade Federal de Goiás (UFG), Goiânia, Goiás, Brasil; aline.da.cruz@live.com; http://orcid.org/0000-0003-0448-3137

3 Universidade Federal de Goiás (UFG), Goiânia, Goiás, Brasil; giovanaalves_2@hotmail.com; http://orcid.org/0000-0001-7493-420X
} 


\title{
Portuguese conjuncture and subordinate loans in Nheengatu
}

\begin{abstract}
Studies show that language loans also occur in grammatical classes, such as conjunctions, according to Muysken (1981) and Matras (2009), although they are more common in lexical classes. This article discusses the accessibility of conjunctions to manifest themselves as loans. For this purpose, an analysis is made of the Brazilian Portuguese (PB) conjuncture loans that are used in Nheengatu (NG). From the comparison between data, loans were identified as that of the adversary "mas" (in Nheengatu, "ma") and the adverb of deictic time "agora", which also acquired, in a grammaticalization process, the function of conjunction of caveat, which was transported to the NG. It was possible to confirm the opening of languages for conjuncture loans and that terms of ambiguous functions in the PB are transported with a more fixed function to the NG.
\end{abstract}

Keywords: linguistic contact; loans; conjunctions; Brazilian Portuguese; Nheengatu.

\section{Introdução}

Estudos sobre contato linguístico têm procurado observar quais estruturas seriam mais propícias a se manifestarem como empréstimo linguístico, particularmente em situações que envolvam assimetria entre duas línguas em contato. Em nossa experiência cotidiana, facilmente observamos palavras pertencentes à classe dos nomes ocorrendo como empréstimos linguísticos. Essa observação empírica confirma-se em estudos tipológicos que propõem hierarquias que procuram prever quais estruturas seriam mais comumente passíveis ao empréstimo entre línguas em contato.

De fato, os nomes constituem a classe lexical mais acessível a empréstimos (cf. MORAVCSIK, 1978; MUYSKEN, 1981, entre outros). Contudo, empréstimos linguísticos não ocorrem exclusivamente com classes lexicais, podendo ocorrer também com estruturas gramaticais. Dentre as classes gramaticais, as conjunções são as que mais frequentemente ocorrem como empréstimo, como vemos, por exemplo, em Muysken (1981), Matras (2009), dentre outros. Ainda que haja um apontamento para a necessidade de estudos sobre empréstimos linguísticos se atentarem para a existência de empréstimos de conjunções, e quiçá permitirem uma maior compreensão sobre o papel desse tipo de empréstimo na reestruturação dos enunciados em situações de intenso contato linguístico, estudos subsequentes procuraram refinar essa hierarquia, procurando identificar, dentre as conjunções, quais seriam mais passíveis de ocorrerem como empréstimo. Com base em uma amostra de vários dialetos de Romani, de línguas em contato com o Árabe e de línguas em contato com o Espanhol Americano, Matras (2009) propõe a seguinte hierarquia de acessibilidade de conjunções a ocorrerem como empréstimo: 
1. Adversativa $>$ alternativa $>$ conjuntiva

$\mathrm{MAS}>\mathrm{OU}>\mathrm{E}$

Essa é uma hierarquia implicacional, ou seja, se uma língua apresenta uma conjunção alternativa como empréstimo, também apresentará uma conjunção adversativa. Se uma língua apresentar uma conjunção conjuntiva como empréstimo, em tese, também deverá apresentar conjunções alternativas e adversativas A alta acessibilidade de conjunções adversativas para empréstimos também é apontada por Stolz, C. e Stolz, T. $(1996,1997)$ em estudos sobre línguas indígenas da América Central.

Embora alguns estudos sobre empréstimos linguísticos no Nheengatu já tenham sido realizados, como vemos em Eldeweiss (1969), em Santos (2020) e em Cruz e Santos (2020), o intuito deste estudo é contribuir, especificamente, para a discussão a respeito da acessibilidade de conjunções a se manifestarem como empréstimos, o que ainda não foi realizado. Mais especificamente, objetiva-se analisar as conjunções, etimologicamente originárias do Português, que são utilizadas como empréstimo em Nheengatu, língua da família Tupi-Guarani, utilizada com língua geral entre os povos Baré, Baniwa e Werekena no Alto do Rio Negro.

Para tanto, este artigo é dividido em três seções. Primeiramente, são descritas as conjunções do Português que ocorrem como empréstimo no Nheengatu. Em seguida, são descritos os subordinadores emprestados ao Nheengatu. Por fim, são apresentadas, em nossas considerações finais, um sumário das principais observações feitas aqui, além da indicação de perspectivas para a continuidade das pesquisas. Completam o texto as referências usadas em nosso estudo.

\section{Empréstimo de conjunções}

De modo geral, Rocha Lima (1992), Cunha e Cintra (2001), dentre outros expoentes dos estudos gramaticais tradicionais, referem-se às conjunções de maneira muito semelhante àquela feita pela Nomenclatura Gramatical Brasileira (NGB). Seguindo, então, essa tendência, as conjunções podem ser definidas, em sentido amplo, como vocábulos gramaticais que servem para relacionar duas orações ou dois termos semelhantes de uma mesma oração. É consenso também, entre autores da tradição gramatical, a classificação das conjunções em dois tipos: as coordenativas e as subordinativas.

As conjunções coordenativas são aquelas que relacionam termos ou orações de idêntica função gramatical (critério sintático) conforme podemos ver, respectivamente, nos exemplos 2 e 3 . As conjunções subordinativas, por sua vez, são as que ligam duas orações, sendo o papel de uma delas o de determinar ou complementar o sentido da outra, ou seja, de funcionar como um termo integrante ou mesmo acessório da oração 
a que está se ligando, o que resulta na percepção de que, entre essas duas orações, há evidentemente uma relação de dependência (sintática e semântica), como se pode notar no exemplo em 4, a seguir:

2. [O tempo] e [a maré] não esperam ninguém.

3. [Chovia muito] ou [o sol brilhava] na hora do casamento?

4. [[Eram três da tarde] [quando cheguei às arenas romanas]].

Partindo, agora, para uma tendência mais atual de estudos gramaticais, de cunho mais funcionalista, retomamos Neves (2000), que define as conjunções no escopo da "junção", o qual compreende as palavras pertencentes à esfera semântica das relações e processos, haja vista atuarem na junção dos elementos do discurso, isto é, ocorrerem em determinado ponto do texto, indicando o modo por meio do qual as partes do discurso que se sucedem se conectam.

Quanto à classificação para as palavras de "junção", a autora estabelece uma tipologia, baseada no estatuto dessas palavras, o qual determina que, se a palavra de junção estiver: a) dentro da estrutura da oração ou dentro de suas subestruturas, serão conjunções as subordinadoras e as conjunções coordenadoras; b) fora da estrutura oracional, isto, no âmbito textual, então serão as conjunções coordenadoras ${ }^{4}$. Os dados, a seguir, todos retirados de Neves (2000), refletem o referido estatuto de cada palavra de junção, conforme a tipologia estabelecida pela própria autora:

5. [[Sempre aproveito para dormir] [quando me obrigam a fazer alguma coisa que não quero].]

6. [[Eu] e [meu marido] fizemos os exames necessários] e [constatamos que o problema era meu].]

7. [[Pecando a gente mitiga mas não derrota o pecado.] [Ou seria preciso pecar muito tenazmente?]]

\footnotetext{
4 Neves (2000) inclui ainda nessa tipologia de palavras as preposições que não se constituem como foco do presente estudo. Todavia, é interessante ressaltar a ideia da autora de que a subordinação estrita ocorreria na complementação e na adjunção, representadas, então, no uso das preposições (entre sintagmas ou entre orações). Já a junção concernente às relações entre satélites adverbiais e seus núcleos (relações como as de tempo, causa, entre outras) se representa não apenas no uso das preposições, mas também no de algumas conjunções designadas tradicionalmente como de subordinação.
} 
Para concluir, mas ainda à luz dos aportes teóricos advindos dos estudos de cunho mais discursivo, referenciamos llari (2015), cuja definição de conjunção passa pelas propriedades semântico-sintáticas dessa classe de palavras e, obviamente, assemelhase muito à proposta de Neves (2000), já que ambos os autores se prendem à noção de "junção" para melhor definir a classe de palavras usadas para estabelecer conexões entre elementos de um texto. Para aquele autor, portanto, as conjunções são palavras dotadas de uma função conectiva, cuja peculiaridade entre os demais conectivos seria a capacidade de se aplicarem a um tipo particular de objetos linguísticos, as orações ${ }^{5}$.

Considerando as propriedades semânticas das conjunções, Castilho (2010) lembranos de que essa classe de palavras, em geral, deriva de advérbios e de outras classes lexicais. Dessa maneira, em consonância com a indagação desse autor, qual seria, então, a contribuição semântica que as conjunções dão às sentenças? Sweetser (1990) estabelece uma relação entre as conjunções inglesas because, and, or, but e os verbos modais para mostrar sua ambiguidade.

\section{Adversativa}

De acordo com Castilho (2010), as orações coordenadas adversativas ou contrajuntivas caracterizam-se pelo fato de que o dito na segunda oração contraria as expectativas geradas na primeira. Essa contrariedade é estabelecida semanticamente pela conjunção adversativa "mas", a qual funciona como um bloqueador da aposição do segundo segmento ao primeiro (DIAS DE MORAES, 1987 apud CASTILHO, 2010), como se pode ver no exemplo do Português Brasileiro:

\section{Pensei que iria ganhar na loteria, mas o "sortudo" foi outro.}

No Nheengatu, a conjunção adversativa ma, empréstimo do Português "mas", também permite estabelecer esse tipo de relação adversativa descrito por Castilho (2010) para o Português. Todos os enunciados em Nheengatu foram retirados de Cruz (2011). No caso dos exemplos abaixo, os enunciados de 9 a 11 ilustram o uso da conjunção. Na última linha de cada exemplo, indicamos também o estatuto do falante em relação às outras línguas em contato.

\footnotetext{
5 A exemplo de Neves (2000), Ilari (2015) ressalta que essa característica basta para distinguir as conjunções das preposições, conectivos que se aplicam a termos da oração. Todavia, o autor lembra e mostra que muitas conjunções ditas coordenativas se associam a sintagmas, como já mostrado em exemplos dados neste artigo.
}

6 Estudos mostram que não há consenso entre os estudiosos sobre o fato de outras conjunções tidas pelas gramáticas como adversativas terem as mesmas propriedades de "mas". Para mais detalhes, consultar Castilho (2010, p. 354). 
9. "poxa yande Werekena, mamãe $\quad$ ma, ti=ya-kua $\quad$ ya-kuntai
INTJ7 nós Werekena, mamãe

'Poxa! Nós somos Warekena, mamãe, mas não sabemos falar.' [Br' , bilíngue (YRL-PB)]. (p.483)

10. $\quad t i=w a ̃=a w a$

$\mathrm{NEG}=\mathrm{PFV}=$ pessoa

ma supi

cONJ com.certeza u-kuntai

3SG.A-contar

suu

animal se-irũ/

ISG.NA-COM

a-kua

1SG.A saber

'Ninguém mais fala comigo, mas na verdade, os nomes de animais, eu sei'. [Wr, bilíngue YRL-Wr] (p.483).

11. imũ

$$
\text { paa u-riku }
$$

x-imiriku

ma ae

ti $=u-r i k u$

3SG.A:irmã

REP 3SG.A-ter

3SG.NA-esposa CONJ ele

$N E G=3 S G \cdot A-t e r$

'Diz que o irmão dele tinha esposa, mas ele não tinha.' [Bn, falante de Bn, YRL, PB] (p.483)

\section{Ressalva}

Como já dito anteriormente, as conjunções geralmente derivam de advérbios, os quais são, ma maior parte das vezes, concebidos em gramáticas tradicionais do Português como palavras modificadoras de outra classe de palavras, o verbo. Segundo Rocha Lima (1992), a função dos advérbios é expressar as várias circunstâncias que cercam a significação verbal ${ }^{9}$. Quanto à classificação, os advérbios se distribuem em termos semânticos pelos seguintes tipos: de dúvida ("talvez", "acaso", "porventura", entre outros);

7 Abreviações: INTJ = interjeição, $C O N J=$ conjunção, NEG = negação, $1 \mathrm{PL}=$ primeira pessoa plural, PFV = perfectivo, REP = reportativo, 3SG = terceira pessoa do singular, $1 S G=$ primeira pessoa do singular, NA = não ativo (índices de pessoa da série ativa usados com complemento de nome, de posposições e de verbos intransitivos estativos flexionáveis e argumento único de verbo transitivo ativo e sujeito de verbo transitivo), $\mathrm{COM}=$ comitativo, $1 \mathrm{SG}=$ primeira pessoa do singular, $\mathrm{REL}=$ relativizador, $\mathrm{DAT}=$ dativo, $\mathrm{DEM}=$ demonstrativo, FIN $=$ finalidade, RESTR $=$ restritivo, $\mathrm{ABLAT}=$ ablativo, $D A T_{\text {prosp }}$ dativo prospectivo, $1 \mathrm{PL} . \mathrm{A}=$ primeira pessoa do plural, $\mathrm{A}=$ ativo, INDF = indefinido, $\mathrm{PL}=$ plural, $\mathrm{FOC}=$ foco, $\mathrm{SUB}=$ subordinador, $\mathrm{FUT}=$ futuro projetado, $\mathrm{NMZ}=$ nominalização.

8 Nos exemplos deste trabalho, utilizam-se siglas para as etnias, são elas: BR para Baré, BN para Baniwa, WR para Werekena.

9 Rocha Lima (1992) lembra, porém, que alguns advérbios de intensidade podem também modificar adjetivos ou mesmo outros advérbios, indicando-lhes o grau. Exemplo: "muito belo" (belíssimo), "vender muito barato" (baratíssimo). 
de intensidade ("muito", "pouco", "bastante", "excessivamente", entre outros); de lugar ("abaixo", "acima", "aí", "aqui", entre outros); de modo ("bem", "mal", "assim", entre outros) e, ainda, de tempo ("ainda", "amanhã", "ontem", entre outros).

Nesta última categoria de advérbios do Português, ou seja, de tempo, inclui-se a palavra "agora", a qual, em um sentido, que podemos chamar de primário, é usada para indicar o momento da enunciação e, por isso, como afirma Castilho (2010) é classificado como advérbio dêitico. No entanto, no Português Brasileiro, a palavra "agora" tem sido também utilizada com a função de conjunção, indicando as funções de ressalva, confronto, contraste, entre outras (CASTILHO, 1997). O processo pelo qual passa o termo "agora"é o da gramaticalização. Nesse processo, elucidado por autores como Meilet (1912 apud LEHMANN, 2015), um termo passa a assumir, numa perspectiva funcional de linguagem, outras funções as quais anteriormente não assumia. Com o avanço dos estudos nessa área, foi proposto que a gramaticalização é um processo unidirecional por meio do qual itens de valor lexical adquirem status de valor gramatical ou morfossintáticos, estabelecendo, desse modo, relações anteriormente não realizadas ou realizadas de outras formas (TRAUGOTT; KÖNIG, 1991). Compreende-se, assim, o estabelecimento de um continuum do "menos gramatical" para o "mais gramatical".

Nesse sentido, para Sweetser (1990), mesmo expressões de alta carga gramatical, como é o caso das conjunções, visto que pertencem à classe de palavras fechadas, liberam, durante o enunciado, cargas de sentido, o que aponta para um processo de gramaticalização. Enfım, tendo em vista que a gramaticalização se configura, basicamente, no processo de mudança de status de um termo, o "agora" anteriormente discutido aqui, ao ser usado, além da função de advérbio dêitico, também pode ser uma conjunção, é assim um termo gramaticalizado.

No discurso Nheengatu, o termo "agora" foi introduzido unicamente com a função de conjunção, expressando o sentido de 'ressalva'10. Os enunciados 12 e 13 são exemplos de orações coordenadas por meio da conjunção agora em Nheengatu:

\begin{tabular}{|c|c|c|c|c|}
\hline a-pudei & a-mbeu & a-kua & waa / & \\
\hline 1SG.A-poder & 1SG.A-contar & 1SG.A-saber & REL & \\
\hline Agora & Tunũ & a-paka & a-maã & yawe=wã \\
\hline CONJ & Tunum & 1SG.A-acordar & 1SG.A-ver & ser.assim=PFV \\
\hline
\end{tabular}

'Posso falar o que sei. Agora, Tunum, eu acordei e vi já assim.' (Wr, monolíngue YRL) (p.484).

10 Para referência dêitica ao tempo de enunciação, utiliza-se o advérbio dêitico kui(ri), 'agora'. 


\begin{tabular}{llll} 
13. & porke aikue & iskola indigenaixe & \multicolumn{2}{c}{ a-aseitai / } \\
CONJ EXIST & escola indígena & eu & 1SG.A-aceitar \\
agora diferensiada & xarã & nhaã & ti=a-kua \\
CONJ diferenciada & eu=DAT & DEM & NEG=1SG.A-saber
\end{tabular}

'Porque haver escola indígena, aceito. Agora, diferenciada para mim, não sei.' [Br, bilíngue YRL-PB) (p.484).

Vale a pena ressaltar que o empréstimo agora é utilizado apenas com a função de conjunção de ressalva. Em Nheengatu, o advérbio de origem Tupi-Guarani kuiri, traduzido como "agora", funciona como advérbio dêitico, conforme ilustrado no exemplo abaixo:
14. kuiri ya-seruka Namuim
agora IPL.A-chamar Anamoim
'Agora chamamos de Anamoim'. (Br, bilíngue YRL-PB) (p.297).

\section{Explicativa e causalidade}

A conjunção coordenativa explicativa, assim como a conjunção subordinativa causal, segundo a Gramática Tradicional do Português, e como outras conjunções, ligam duas orações estabelecendo entre elas algum tipo de relação. Segundo Almeida (1965), a conjunção coordenativa explicativa introduz a segunda oração para explanar ou dar continuidade ao sentido da primeira oração, como podemos ver no exemplo em 15:

15. Morreu, ou seja, deixou de incomodar-nos.

A conjunção subordinativa causal, por sua vez, liga uma oração a outra em uma relação de dependência, tal "como o efeito depende da causa". A oração que indica o efeito é chamada de principal; já a que representa a causa é denominada de subordinada, como no exemplo em 16, a seguir:

\section{Dei-lho porque me pediu.}

A distinção tipológica entre "ou seja", no exemplo 14, e "porque", em 15, a princípio, pode não trazer dúvidas sobre as funções específicas dessas conjunções, conforme a definição dada pela Gramática Tradicional. Contudo, em se tratando da conjunção "porque" e equivalentes ("como que" ou "pois que"), é preciso lembrar que tal distinção não se faz de maneira considerada tranquila. Afinal, segundo a própria NGB, essas conjunções ora possuem valor de coordenativas explicativas, ora de subordinativas causais. 
A respeito dessa polêmica, parece-nos que Neves (2000) reafirma, de certa maneira, o que a NGB diz sobre as relações expressas pelas conjunções ditas causais. De acordo com a autora, a relação causal diz respeito à conexão causa-consequência, ou causa-efeito, existente entre dois eventos. Tais relações ocorrem entre predicações (isto é, estado de coisas), indicando uma causa real, eficiente ou efetiva. Dessa forma, a relação causal entre os dois eventos implicaria uma subsequência temporal ${ }^{11}$ do efeito em relação à causa. É o que notamos, assim, no exemplo 16, em que o evento "dei-lho" é posterior à causa "me pediu".

Neves (2000) lembra-nos, ainda, que as expressões linguísticas de ligação causal restringem-se ao que está chamando de causalidade efetiva entre conteúdos. As relações ditas, essencialmente, causais, raramente se referem a simples acontecimentos ou a situações de mundo. Segundo essa autora, tais relações também podem ser marcadas por um conhecimento existente no domínio epistêmico do falante. Notemos o exemplo em (17):

17. A opção de usar frango para alimentação de peixes pode não ser boa, porque há excesso de proteína na carne da ave.

Como ressalta Neves (2000), por ocorrerem também entre fatos possíveis (não somente entre estados de coisas), essas relações (chamadas tradicionalmente de "causas formais") dependem da avaliação do falante. Além disso, esse tipo de relação pode ocorrer entre um ato de fala e a expressão da causa que motivou tal ato linguístico. Assim, por exemplo, na chamada oração principal, pode ocorrer um ato de fala declarativo, como no exemplo em 18; um ato de fala interrogativo, como em 19, ou, ainda, um ato de fala injuntivo (dêitico ou imperativo), como vemos em 20, respectivamente.

18. Vou tirar umas férias, porque estou cansadíssimo.

19. Muito conveniente, não é? Porque aí saiu todo o mundo, você ficou lá, sozinho com o retratista...

20. Vai, vai, que já vai tarde.

Como afirma Neves (2000), construções como as expressas nos exemplos acima são consideradas, na tradição gramatical, dentro da coordenação, pois não preveem a

11 Neves (2000) adverte que a relação causal entre conteúdos, isto é, a chamada "causa efetiva" não, necessariamente, envolve tempo, pois pode dar-se entre estados de coisas considerados não dinâmicos. Exemplo: "Mas o caso americano é sui-generis porque não há políticos no país". 
articulação simples de orações, mas sim de períodos, em que há a representação de vários atos de fala. Por isso, defende a autora, justifica-se a denominação conjunção explicativa, em vez de causal, para os termos grifados nos exemplos 18 - 19. Afinal, na relação de causalidade entre os diferentes atos de fala não se percebe a causalidade real, efetiva, material, eficiente, e tampouco a causalidade emanada da visão dos fatos do falante. Trata-se de uma relação mais frouxa ${ }^{12}$ do que uma relação verdadeiramente causal (em qualquer de suas subespécies, como "motivo", "razão", "justificativa", entre outras), muito mais próxima de uma explicação.

Em Nheengatu, a oração coordenada com a conjunção porke (explicativa) permite introduzir uma explicação para o trecho discursivo. É usada até mesmo por falantes com baixa fluência em Português. Os enunciados 21 e 22 ilustram o uso da conjunção explicativa porke:

$\begin{array}{lllll}\text { 21. } & \text { ya-kuntai } & \text { Portugues } & \text { ya-mundu } & \text { arã / } \\ \text { IPL.A-falar } & \text { Português } & \text { IPL.A-mandar } & \text { FIN } & \\ \text { porke } & \text { yande } & \text { ya-kua } & \text { yane-nheenga=ntu } & \text { ti=u-meẽ } \\ \text { CONJ } & \text { nós } & \text { IPL.A-saber } & \text { IPL.NA-língua=RESTR } & \text { NEG=3sg } \text { Adar }^{-}\end{array}$

'Falamos Português para mandarmos, porque sabermos somente nossa língua, não dá' [Bn, falante de Bn, Nh, PB] (p.485).

\begin{tabular}{|c|c|c|c|c|}
\hline ape & paa & yakare & u-tumai=wã & i-sui / \\
\hline aí & REP & jacaré & 3SG.A-tomar=PFV & 3SG.NA-ABLAT \\
\hline porke & panhe & u-putai & u-iku & tata \\
\hline CONJ & todo & 3SG.A-querer & 3SG.A-estar & fogo \\
\hline
\end{tabular}

'Aí o jacaré tomou dele, porque todos estavam querendo o fogo.' [Br, bilíngue YRL-PB] (p.485).

A língua também disponibiliza uma forma nativa de expressar a causa de um evento. Tratase da subordinação por meio da conjunção nhanse. Em geral, a conjunção nhanse tende a ser substituída pelo empréstimo porke. Apesar disso, ainda ocorre espontaneamente em discursos orais produzidos por mulheres monolíngues, como ilustrado em 23 e 24:

12 Neves (2000) reforça que a relação expressa pelas conjunções nesses exemplos seria mais "frouxa" do que a que observamos no exemplo 20, inclusive por ser sensível na formação de duas curvas entoacionais nessas construções, cada uma delas referente a um dos dois atos de fala, os quais se separam por pausa, o que, em geral, registra-se, na escrita, por meio de sinal de pontuação (vírgula, ponto e vírgula ou mesmo, ponto final). 
23. a-saisu

1SG.A-amar

panhe

todo kua se-iwi

DEM 1SG.NA-terra

maã a-viveri

coisa $1 \mathrm{sg}_{\mathrm{A}}$-viver nhanse ae i-sui a-yuka

CONJ ele 3SG.NA-ABLAT 1SG.A-tirar

arã

DAT $_{\text {PROSP }}$

'Amo esta minha terra, porque dela tiro tudo para viver'. [Bn, falante de Bn, YRL, PB] (p.486)

24. a-saisu

ISG.A-amar

nhanse

CONJ kua

DEM

ti=presizu

NEG=é.preciso yane-iwi /

IPL.NA-terra

ya-piripana maã 13

IPL.A-comprar coisa

'Amo esta minha terra, porque não precisamos comprar nada.' [Bn, falante de Bn, YRL, PB] (p.486)

Em registros escritos, a conjunção nhanse é conscientemente empregada para substituir o empréstimo porke. O enunciado 25 foi, no ano de 2007, produzido por professores durante o curso de Magistério Indígena, traduzindo um depoimento, originalmente produzido em Português, com emprego da conjunção do Português porque.

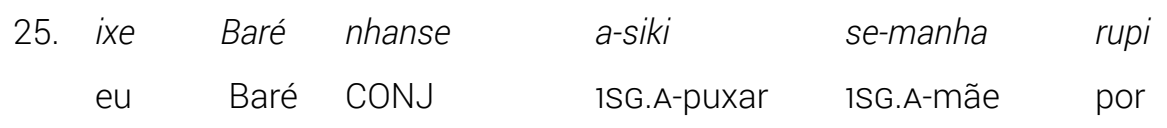

'Eu sou Baré, porque puxo pela minha mãe.' [Br, bilíngue YRL-PB] (p.486).

Como já dissemos, a NGB trata as orações que introduzem uma explicação como orações coordenadas explicativas, enquanto as que introduzem a causa de um evento são tratadas como orações subordinadas causais ${ }^{14}$. No Português e, por convergência sintática no Nheengatu, a distinção entre os supostos dois tipos de estruturas que relacionam as orações é bastante tênue e se dá no nível semântico, mas não no nível sintático. A relação entre coordenação e subordinação se estabelece em um continuum semântico, não havendo necessariamente um critério de corte bem estabelecido. Neste trabalho, não serão levadas em conta as minúcias semânticas da gramática tradicional para

13 A forma presizu é um empréstimo verbal que ocorre como partícula modalizadora em Nheengatu. Para um estudo acerca de empréstimos verbais que ocorrem como partículas modalizadoras, cf. Cruz e Santos (2020).

14 "As conjunções que, porque, porquanto, etc. ora têm valor coordenativo, ora subordinativo; no primeiro caso, chama-se explicativas, no segundo, causais" (NOMENCLATURA GRAMATICAL BRASILEIRA, 1959). 
distinguir entre explicação e causa. A rigor, causa é apenas um dos tipos de explicação. Como a influência de estruturas do Português no Nheengatu é mais comum no nível da coordenação do que na subordinação, as estruturas com porke serão consideradas orações coordenadas explicativas.

\section{Alternativa}

Conforme os estudos propostos por Neves (2000), a conjunção alternativa "ou" é utilizada para marcar uma disjunção ou uma alternância entre o elemento em que é usada a conjunção e o elemento que o precede. O processo de alternância ocorrerá entre palavras, entre sintagmas nominais, verbais, adverbiais e adjetivos, entre orações e entre enunciados.

A relação de alternância entre duas orações é estabelecida por ou "conjunção de alternância", empréstimo do Português ou esse empréstimo ocorre, principalmente, na fala de adolescentes, como em 26, e na de pessoas que vivem na zona urbana de São Gabriel da Cachoeira, como em 27. Na fala de pessoas mais velhas, a coordenação alternativa não ocorre, exceto em construções que podem ser caracterizadas como código misto, como em 28:

\begin{tabular}{|c|c|c|c|c|}
\hline kua & tempu & tu-resebei=wã & kua & farda ${ }^{15}$ \\
\hline DEM & tempo & 3PL.A-receber=PFV & DEM & uniforme \\
\hline u & ti=ta-resebei & farda & & \\
\hline CONJ & NEG=3PL.A-receber & uniforme & & \\
\hline
\end{tabular}

'Neste tempo, recebiam já uniforme ou não recebiam uniforme?' [Wr, bilíngue PB-YRL] (p.488).

$\begin{array}{lllllll}\text { 27. u-manduai } & \text { u-defendei arã yepe parti garimpeiru ita } \\ \text { 3SG.A-lembrar } & \text { 3SG.A-defender FIN INDF parte garimpeiro } & \text { PL } \\ \text { u yepe parti emprezariu } & & & & \\ \text { CONJ INDF parte empresário } & & & \end{array}$

'Pensou em defender uma parte dos garimpeiros ou uma parte dos empresários' [Br, bilíngue PB-YRL] (p.488).

15 A expressão kua tempo, formada pelo demonstrativo e pelo empréstimo nominal tempu, é empregada com o sentido de "atualmente", ou seja, um presente mais duradouro do que o expresso pelo advérbio dêitico kuiri 'agora'. 


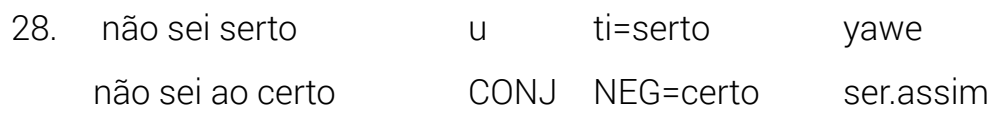

'Não sei se certo ou não certo, assim...' [Wr, monolíngue YRL; PB aprendido quando adulto] (p.488).

\section{Aditiva}

Como visto na Introdução, a terceira conjunção mais comumente utilizada como empréstimo entre as línguas indígenas faladas em territórios colonizados por povos falantes de Português e Espanhol é a conjunção e. De fato, em Nheengatu, encontra-se o empréstimo i. No entanto, essa conjunção aparece apenas na fala de pessoas que apreenderam o Nheengatu como segunda língua já como adultos, sendo sistematicamente corrigida pelos falantes nativos. Para os falantes nativos, e $>i$ deve ser substituído por sintagmas posposicionais com irũ, quando se trata de adjunção de sintagmas nominais como ilustrado em (29).

$\begin{array}{lllll}\text { 29. ape paa } & \text { ai } & \text { yawuti irũ tau-manduai } \\ \text { CONJ REP } & \text { preguiça } & \text { jabuti COM } & \text { 3PL.A-lembrar } \\ \text { tau-munhã } & \text { arã yepe } & \text { kupixa / } & \\ \text { 3PL.A-fazer } & \text { FIN INDF } & \text { roça } & \\ \text { ape te } & \text { ai } & \text { u-su } & \\ \text { CONJ FOC } & \text { preguiça } & \text { 3SG.A-ir }\end{array}$

'Aí, diz que a preguiça e o jabuti resolveram fazer uma roça. Aí, diz que a preguiça foi.' [Br, bilíngue YRL-PB] (p.385).

\section{Subordinador}

As conjunções subordinativas, ou subordinadoras, têm, em sua funcionalidade, a capacidade de exercer uma relação de dependência sintática entre os constituintes relacionados. Conforme Kortmann (1994), a função dos subordinadores é a de especificar as relações entre os termos constituintes da oração, embora estudos como o de Matthiessen e Thompson (1988) já demonstrem a capacidade das conjunções adverbiais atuarem entre sintagmas e "porções maiores do discurso" e não somente orações.

Tendo isso em vista, Neves (2000) elenca os subordinadores no Português Brasileiro conforme as relações semânticas que estabelecem, são elas: relações de tempo, causa, condição, concessão, finalidade, comparação, consecução, conformação, proporção e modo. Neste trabalho, trataremos do empréstimo de conjunções adverbiais concessivas do PB para o NG. 


\section{Concessiva}

Os estudos gramaticais tradicionais chamam de oração subordinada adverbial concessiva aquela que se liga a uma outra oração, dita principal, por meio de uma conjunção subordinativa que expresse a circunstância de concessão (ALMEIDA, 1965), como podemos ver nos exemplos:

30. Ainda que enterrem a verdade, a virtude não se sepulta.

31. Eu sairei, embora ele entre.

A oração subordinada adverbial concessiva é identificada morfologicamente pelo subordinador soki "concessivo", empréstimo do Português "só que". Não apenas houve transferência de forma e sentido, mas também de estrutura sintática: a oração subordinada é posposta à oração principal e o subordinador ocorre no início da subordinada. Os enunciados 32 a 34 ilustram orações subordinadas adverbiais concessivas.

\begin{tabular}{|c|c|c|c|}
\hline ape & u-nheengai & u-iku & apiga \\
\hline $\mathrm{CONJ}$ & 3SG.A-cantar & 3SG.A-estar & homem \\
\hline soki & ti=a-pudei & $a-n$ & \\
\hline SUB & NEG $=1 S G \cdot A-p o d e$ & ISG & ontar \\
\hline
\end{tabular}

'Aí, estava cantando o nome do homem só que não podia contar.' [Wr, bilíngue YRL-PB] (p. 509).

33. inde re-nasei se-sui / soki inde nunca kuri

você 2SG.A-nascer 1SG.NA-ABLAT SUB você nunca FUT

$\begin{array}{lllllll}\text { re-su } & \text { re-yuká } & \text { bũwa } & \text { piri wal } & \text { nhaã pirá } & \\ \text { 2SG.A-ir } & \text { 2SG.A-matar } & \text { ser.abundante } & \text { ser.mais } & \text { REL } & \text { DEM peixe }\end{array}$

'Você nasceu de mim, só que você nunca vai matar um peixe que é maior (do que você).'[Br, bilíngue YRL-PB] (p. 509).

34. ya-sendu ya-sendu /

$\begin{array}{lll}\text { IPL.A-escutar } & \text { IPL.A-escutar } & \\ \text { soki } & \text { ti }=\text { ya-compreendei } & \text { maye-sa } \\ \text { SUB } & \text { NEG }=1 \mathrm{pl}_{\mathrm{A}} \text {-compreender } & \text { ser.como-NMZ }\end{array}$

'Escutar, escutamos, só que não compreendemos o que é dito.' Lit.: Escutamos, escutamos, só que não compreendemos o como. [Wr] (p. 510). 
Em termos semânticos, a interpretação pode ser de concessiva ou de adversativa. $\mathrm{Na}$ interpretação concessiva propriamente dita, a oração principal expressa um evento como sendo real 'O homem está cantando', em 32, e 'o ouvinte nasceu da falante', em 33. $\mathrm{Na}$ interpretação adversativa, a verdade está na subordinada "nós não compreendemos o que é dito", em 34, que contradiz a principal. Porém, trata-se de uma adversativa que compromete menos o grau de verdade da proposição da principal, do que uma oração adversativa com a conjunção "mas", vista na seção das adversativas.

\section{Considerações finais}

Este artigo discutiu a possibilidade de as conjunções se manifestarem como empréstimos linguísticos, a despeito de geralmente esse processo ser mais comum com classes lexicais. Contudo, como previsto por Muysken (1981) e Matras (2009), isso também pode ocorrer em classe fechadas, como é o caso das conjunções.

De fato, a breve comparação entre dados da língua Nheengatu (NG) e do Português Brasileiro (PB) permitiu-nos identificar empréstimos envolvendo as classes gramaticais conjunção e também a classe de advérbios. Assim, nosso estudo confirma a abertura das línguas para empréstimos de conjunções, como vimos no exemplo da adversativa "mas", que se manifesta em Nheengatu por meio da forma ma. Além disso, também vimos que termos de funções ambíguas no PB podem ser emprestados por outras línguas com função mais delimitada, como é o caso do advérbio de tempo dêitico "agora", que ao ser transportada para o NG, passou a receber também a função de conjunção de ressalva, após um processo de gramaticalização.

Também com base nos dados aqui elencados e nas análises realizadas, além da tendência da classe das conjunções de se manifestarem como empréstimo linguístico, pudemos confirmar a hierarquia estabelecida por Matras (2009) a respeito da ordem implicacional de tais empréstimos. Levando em conta esse pressuposto teórico, uma vez mais podemos citar, em NG, o exemplo da conjunção de contraste ma, emprestada do PB "mas", como a adversativa mais prototípica da língua fonte. Ocupando o segundo lugar na hierarquia proposta por Matras (2009) estão as conjunções alternativas. De fato, a forma "ou" também ocorre principalmente com falantes com pouca fluência em Português.

Dessa forma, esse artigo pode contribuir para lançar mais clareza sobre o tema apresentado. Por outro lado, é necessário reconhecer que os resultados alcançados, ainda que incipientes, também apontam para a necessidade de mais pesquisas sobre o tema. Afinal, no Brasil, há cerca de 274 línguas autodeclaradas, sendo que uma parte significante delas encontra-se em intenso contato com o Português.

Isso nos leva a crer que muitas outras línguas brasileiras, assim como o Nheengatu, possam apresentar empréstimos de conjunções e/ou de outra classe gramatical com 
menor incidência para ser emprestada. Como esse ainda é um tema muito pouco explorado dentro da área da linguística de contato no Brasil, aponta-se para a necessidade de ampliar esses estudos, na interlocução entre estudiosos de línguas indígenas e de Português, principalmente em uma perspectiva funcional.

\section{REFERÊNCIAS}

ALMEIDA, N. P. Gramática Metódica da Língua Portuguesa. São Paulo: Saraiva, 1965.

CASTILHO, A. T. Gramática do Português Brasileiro. São Paulo: Contexto, 2010.

CASTILHO, A. T. Língua falada e gramaticalização. Filologia e linguística portuguesa, n. 1, p. 107-120, 1997.

CRUZ, A.; SANTOS, B. H. L. de P. E do verbo fez-se partículas em Nheengatú. Boletim do Museu Paraense Emílio Goeldi. Série Ciências Humanas, 2020.

CRUZ, A. Fonologia e gramática do Nheengatu: a língua geral falada pelos povos Baré, Warekena e Baniwa. 2011. Tese (Doutorado em Linguística) - Vrije Universiteit, Utrecht, 2011.

CUNHA, C.; CINTRA, L. F. L. Nova Gramática do Português Contemporâneo. Rio de Janeiro: Nova Fronteira, 2001.

DIAS DE MORAES, L. Nexos de coordenação na fala urbana culta de São Paulo. 1987. Tese (Doutorado em Linguística) - Faculdade de Filosofia, Letras e Ciências Humanas, Universidade de São Paulo, São Paulo, 1987.

EDELWEISS, F. G. Estudos Tupis e Tupi-Guaranis: confrontos e revisões. Rio de Janeiro: Livraria Brasiliana Editora, 1969.

ILARI, R. As conjunções. In: ILARI, R. (org.). Palavras de Classe Fechada. Gramática do Português Culto Falado no Brasil. São Paulo: Contexto, 2015. p. 311-356.

KORTMANN, B. Adverbial Subordinators in the Languages of Europe. Towards a Typology and History. Eurotyp Working Papers, v. 8, 1994.

LEHMANN, C. Thoughts on grammaticalization. 3. ed. Berlin: Language Science Press, 2015. 
MATHIESSEN, C.; THOMPSON, S. A. The structure of discourse and subordination. In: HAIMAN, J.; THOMPSON, S. A. (org.). Clause Combining in Grammar and Discourse. Amsterdam: John Benjamins, 1988. p. 275-329.

MATRAS, Y. Language Contact. Cambridge: Cambridge University Press, 2009.

MEILLET, A. L'évolution des formes grammaticales. Scientia (Rivista di Scienza), v. 12, n. 26, 1912. Reprint in Linguistique historique et linguistique Générale. Paris: Librairie Honoré Champion, 1965

MORAVCSIK, E. Language contact. In: GREENBERG, J. P.; FERGUSON, C. A.; MORAVCSIK, E. A. (org.). Universals of human language. Califórnia: Stanford University Press, 1978. p. 93-122.

MUYSKEN, P. Halfway Between Quechua and Spanish: The Case for Relexification. In: HIGHFIELD, A. R.; VALDMAN, A. (org.). Historicity and variation in Creole studies. Karoma Publishers, Incorporated, 1981. p. 52-69.

NEVES, M. H. M. Gramática de Usos do Português. São Paulo: Editora UNESP, 2000.

ROCHA LIMA, C. H. Nova Gramática da Língua Portuguesa. 31. ed. Rio de Janeiro: José Olympio, 1992.

SANTOS, B. H. L. de P. Empréstimos Lexicais do Português para a Língua Geral: século XVI ao $X X I$. 2020. Dissertação. (Mestrado em Linguística) - Instituto de Letras, Universidade de Brasília, Brasília, 2020.

STOLZ, C.; STOLZ, T. Funktionswortentlehnung in Mesoamerika Spanisch-amerindischer Sprachkontakt (Hispanoindiana II). Berlin: STUF - Language Typology and Universals, v. 49, n. 1, p. 86-123, 1996.

STOLZ, C.; STOLZ, T. Von Manila über Lima bis Mexiko und zurück: Muster bei der Entlehnung spanisher Funktionswörter in die indigenen Sprachen Amerikas un Austronesiens. Philadelphia: Orbis, v. 39, p. 1-77, 1997.

SWEETSER, E. From Etymology to Pragmatics Metaphorical and cultural aspects of semantic structure. Cambridge: Cambridge University Press, 1990.

TRAUGOTT, E. C.; KÖNIG, E. The semantics-pragmatics of grammaticalization revisited. In: TRAUGOTT, E. C.; HEINE, B. (org.). Approaches to grammaticalization. v. 1. Amsterdam: John Benjamins Publishing Company,1991. p. 189-218. 